\title{
Influence of Contrast Media on Bone Mineral Density (BMD) Measurements from Routine Contrast-Enhanced MDCT Datasets using a Phantom-less BMD Measurement Tool
}

\author{
Einfluss der intravenösen Kontrastmittelgabe auf \\ phantomlose Knochendichtemessungen im Routine-MDCT
}

Authors

Andrea Toelly', Constanze Bardach ${ }^{1}$, Michael Weber ${ }^{1}$, Rui Gong², Yanbo Lai², Pei Wang², Yulin Guo², Jan Kirschke³, Thomas Baum ${ }^{4}$, Michael Gruber ${ }^{1}$

Affiliations

1 Department of Biomedical Imaging and Image-guided Therapy, Medical University of Vienna, Austria

2 Department of Radiology, General Hospital of Ningxia Medical University, Yinchuan, China

3 Department of Neuroradiology, Technical University Munich, Germany

4 Department of Diagnostic and Interventional Radiology, Technical University Munich, Germany

Key words

phantom-less, routine $\mathrm{CT}$, contrast agents, calculation formula, bone mineral density

received 02.11 .2016

accepted 21.01.2017

Bibliography

DOI http://dx.doi.org/10.1055/s-0043-102941

Published online: 26.4 .2017 | Fortschr Röntgenstr 2017; 189:

537-543 @ Georg Thieme Verlag KG Stuttgart · New York ISSN 1438-9029

Correspondence

Dr. Andrea Toelly

Department of Biomedical Imaging and Image-guided

Therapy, Medical University of Vienna

Waehringer Guertel 18-20

1090 Wien

Austria

Tel.: + 43/4040048180

andrea.toelly@meduniwien.ac.at

\section{ZUSAMMENFASSUNG}

Ziel Ziel der Studie war den Einfluss einer intravenösen Kontrastmittelgabe auf phantomlos gemessene volumetrische Knochendichtewerte im Routine-MDCT zu evaluieren. Zusätzlich sollte eine Formel zur Berechnung der wahrheitsgetreuen Knochendichte aus arteriell und venös gemessenen Werten aufgestellt werden.
Material und Methodik 112 postmenopausale Frauen im Alter von 40 bis 77 Jahren (mittleres Alter 57,31; SD 9,61), die ein triphasisches MDCT (nativ, arteriell und venös) auf Grund einer anderen klinischen Indikation erhalten haben, wurden inkludiert. Retrospektiv wurden mit Hilfe einer Software zur phantomlosen volumetrischen Knochendichtebestimmung die Knochendichtewerte der Wirbelkörper Th12 bis L4 bestimmt.

Ergebnisse Der mittlere Knochendichtewert in der nativen Phase betrug $79,76 \mathrm{mg} / \mathrm{cm}^{3}$ (SD 31,20), in der arteriellen Phase $85,09 \mathrm{mg} / \mathrm{cm}^{3}$ (SD 31,61) und in der venösen Phase $86,18 \mathrm{mg} / \mathrm{cm}^{3}$ (SD 31,30). Es zeigte sich ein signifikanter Unterschied $(p<0,001)$ zwischen Knochendichtewerten in der nativen vs. Knochendichtewerten, welche in der arteriellen und venösen Phase gemessen wurden. Der Unterschied zwischen arteriell und venös gemessenen Knochendichtewerten war jedoch nicht signifikant $(p=0,228)$. Mittels linearer Regression konnte eine Formel zur Berechnung der wahrheitsgetreuen Knochendichte bei arteriell und venös gemessenen Knochendichtewerten aufgestellt werden: Knochendichte $=-2,287+0,964 *$ [arteriell gemessener Knochendichtewert] und $-4,517+0,978 *$ [venös gemessener Knochendichtewert]. Die Intraobserver-Variabilität wurde mit einem Intraklassen-Korrelationskoeffizienten (ICC) von 0,984 berechnet. Der ICC für die Interobserver-Variabilität betrug 0,991.

Schlussfolgerung Eine intravenöse Kontrastmittelgabe führt zu signifikant höheren phantomlos gemessenen Knochendichtewerten im Routine-MDCT verglichen zu nativ gemessenen Knochendichtewerten. Mit Hilfe der in dieser Studie generierten Formeln kann der wahrheitsgetreue Knochendichtewert jedoch berechnet werden. Zwischen arteriell und venös gemessenen Knochendichtewerten zeigte sich keine signifikante Differenz.

\section{Kernaussagen}

- Knochendichtewerte können mittels spezieller Software an phantomlosen Routine-MDCTs bestimmt werden.

- Intravenöses Kontrastmittel führt zu einer signifikanten Steigerung der an Routine-CT-Untersuchungen gemessenen Knochendichtewerte. 
- Keine signifikante Differenz zwischen Knochendichtemessungen in der arteriellen und der venösen Phase.

- Formeln zur Berechnung einer wahrheitsgetreuen Knochendichte konnten akquiriert werden.

- Die Software zur phantomlosen Knochendichtebestimmung ist eine vielversprechende Methode mit guter Reliabilität.

\section{ABSTRACT}

Aim To evaluate the differences in phantom-less bone mineral density (BMD) measurements in contrast-enhanced routine MDCT scans at different contrast phases, and to develop an algorithm for calculating a reliable BMD value.

Materials and Methods 112 postmenopausal women from the age of 40 to 77 years (mean age: 57.31 years; SD 9.61) who underwent a clinically indicated MDCT scan, consisting of an unenhanced, an arterial, and a venous phase, were included. A retrospective analysis of the BMD values of the Th12 to L4 vertebrae in each phase was performed using a commercially available phantom-less measurement tool.

Results The mean BMD value in the unenhanced MDCT scans was $79.76 \mathrm{mg} / \mathrm{cm}^{3}$ (SD 31.20), in the arterial phase it was $85.09 \mathrm{mg} / \mathrm{cm}^{3}$ (SD 31.61), and in the venous phase it was $86.18 \mathrm{mg} / \mathrm{cm}^{3}$ (SD 31.30). A significant difference $(p<0.001)$ was found between BMD values on unenhanced and contrastenhanced MDCT scans. There was no significant difference between BMD values in the arterial and venous phases $(p=0.228)$. The following conversion formulas were calculat- ed using linear regression: unenhanced $\mathrm{BMD}=-2.287+0.964$ * [arterial BMD value] and $-4.517+0.978 *$ [venous BMD value]. The intrarater agreement of BMD measurements was calculated with an intraclass correlation (ICC) of 0.984 and the interobserver reliability was calculated with an ICC of 0.991 .

Conclusion Phantom-less BMD measurements in contrastenhanced MDCT scans result in increased mean BMD values, but, with the formulas applied in our study, a reliable BMD value can be calculated. However, the mean BMD values did not differ significantly between the arterial and venous phases.

\section{Key points}

- BMD can be assessed on routine CT scans using a phantom-less tool.

- i. v. contrast agent significantly elevates BMD values measured on routine CT scans.

- BMD values measured in the arterial and venous phase did not differ significantly.

- Conversion formulas were defined for the calculation of a reliable BMD.

- The phantom-less tool showed good reliability and is a promising method.

\section{Citation Format}

- Toelly A, Bardach C, Weber M et al. Influence of Contrast Media on Bone Mineral Density (BMD) Measurements from Routine Contrast-Enhanced MDCT Datasets using a Phantom-less BMD Measurement Tool. Fortschr Röntgenstr 2017; 189: 537-543

\section{Introduction}

Osteoporosis is characterized by a lowered bone mass and trabecular thinning, which leads to an increased risk of fracture, higher mortality, and increased healthcare costs. In addition, patients with osteoporosis suffer from decreased independence and quality of life [1 - 4].

Osteoporosis is diagnosed by the assessment of bone mineral density (BMD). Commonly used BMD measurements are dualenergy X-ray absorptiometry (DXA) and quantitative computed tomography (QCT). A major problem with DXA is that in elderly populations lumbar spine spondylosis causes false elevation of BMD when measured in this anatomical site. [2, 5-8].

Recent studies have shown that routinely performed multidetector computed tomography (MDCT) scans can also be used for BMD measurements $[9,10]$. As MDCT is one of the most important radiological examination methods, especially in tumor patients, and oncology patients also frequently suffer from osteoporosis triggered by chemotherapy or hormonal therapy, BMD measurements obtained on routine MDCT scans would be a promising method for the diagnosis of osteoporosis [11, 12]. A very recent innovation in this field was the development of phantomless BMD measurement systems. The major advantage of this phantom-less BMD measurement system is that the patient can be used as his/her own reference, so that no bone equivalent phantom is necessary, and, consequently, BMD can be measured retrospectively on MDCT scans initially performed for another reason. This saves the patient from additional radiation exposure. Furthermore, beam-hardening and scatter effects, which might be induced by an external phantom, do not play a role in phantom-less BMD measurement methods [13, 14].

However, it must be stated that there are potential problems with phantom-less BMD methods. For example, heterogeneous or varying density values of muscle and fat, which are used as reference standards, due to differences in hydration status can influence the measurements [14]. In accordance with that, previous studies have already shown that intravenous contrast media administration also leads to higher BMD values measured on routine MDCT scans [15 - 18]. As oncologic staging investigations are mainly performed with the use of an intravenous contrast agent, this could be a major drawback for the diagnosis of osteoporosis on routine MDCT scans.

Therefore, the aim of our study was to evaluate the differences in phantom-less BMD measurements on routine MDCT scans in the unenhanced, arterial, and venous contrast phases, using the Philips BMD measurement tool (Philips Healthcare, Best, NL). Furthermore, an algorithm for calculating a reliable BMD value from these contrast-enhanced MDCT scans should be developed. 


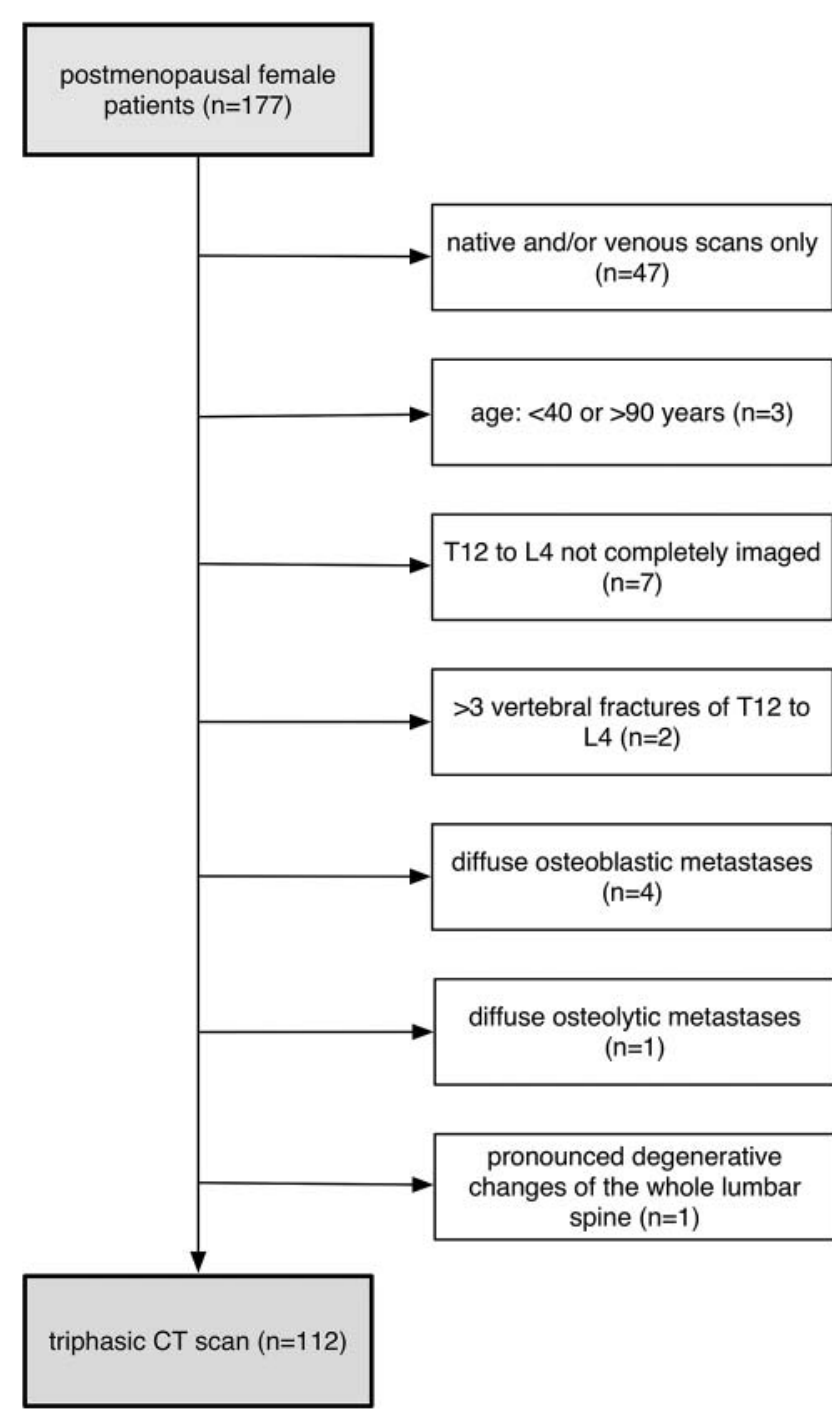

- Fig. 1 Flowchart of inclusion and exclusion of study participants.

- Abb. 1 Flussdiagramm der Ein- und Ausschlusskriterien.

\section{Materials and Methods}

\section{Patients}

In this prospective study, we included 112 female, postmenopausal patients from the age of 40 to 77 years (mean age: 57.31 years; SD 9.61), who underwent a routinely performed contrastenhanced MDCT scan for other indications in the period from November 2013 to June 2014. The inclusion criteria were a contrastenhanced MDCT scan, consisting of at least an unenhanced, an arterial and a venous phase, and a scan region including vertebrae T12 to L4. A flowchart of excluded patients is depicted in > Fig. 1. Indications for the MDCT scans were, for example, nausea, abdominal pain, portal venous thrombosis and intestinal obstruction as well as follow-up examinations for ovarian, colon, gastric and lung cancer. In total, 61 patients were oncologic patients, 59 of which were undergoing chemotherapy. 6 patients were smo- kers. Only vertebrae T12 to L4 were included in the BMD analyses. Patients with metastases or hematologic or metabolic bone disorders besides osteoporosis were excluded. Furthermore, 16 vertebrae with benign osteolytic or osteoblastic lesions, for example, hemangiomas, 17 fractured vertebrae, and 4 vertebrae with pronounced degenerative changes were excluded. In one patient we had to exclude one vertebra because of a vertebroplasty. In total, at least two vertebrae in each patient had to be evaluable.

All patients gave written, informed consent to scientific evaluation of their data. The local ethics committee approved this prospective study.

\section{Image acquisition}

The MDCT scans were performed on a 256-row CT unit (Philips iCT 256, Philips Healthcare, Best, NL). The scanning protocol was adapted to the clinical indications. The images were acquired with a tube voltage of $120 \mathrm{kV}$, an average tube current of $200 \mathrm{mAs}$, and a collimation of $128 \times 0.625 \mathrm{~mm}$. Examinations were performed using contiguous acquisition (no overlap). Axial slices were reconstructed using a soft-tissue kernel and a slice thickness of $5 \mathrm{~mm}$. Zips or metal clips were avoided in the field of view (FOV). For the contrast-enhanced series, we chose a standardized amount of contrast agent. Each patient received $100 \mathrm{ml}$ of intravenous contrast media (Omnipaque $300 \mathrm{mg} / \mathrm{ml}, \mathrm{GE}$ Healthcare, Little Chalfont, UK). For the injection, we used a Medrad injector with a flow rate of $3.0 \mathrm{ml} /$ second. The intravenous contrast media injection started with a delay of 35 seconds for the arterial phase and 70 seconds for the venous phase. Only MDCT scans including unenhanced, arterial, and venous phases were included.

\section{Image analyses}

The BMD analyses were performed on a workstation, on which the required phantom-less Philips bone mineral density application was installed previously.

Initially, the correct slice and height of the region of the vertebral body, which should be measured at a safe distance from the cortical bone and tilted to the axis of the vertebra, was adjusted in the axial, coronal, and sagittal planes. An oval region of interest (ROI) was placed in the vertebral body on the axial plane, without including cortical bone and basivertebral veins. Subsequently, a second ROI was placed in the paravertebral muscle and a third ROI in the subcutaneous fat tissue ( $\vee$ Fig. 2, 3). If the paravertebral muscle showed fatty atrophy of more than $50 \%$, the second ROI was placed in the psoas muscle.

The BMD was calculated according to an algorithm that is implemented in the phantom-less BMD measurement tool [14]. All vertebrae were analyzed in each phase, including the unenhanced, arterial, and venous phases.

The calculated BMD value for each evaluated vertebra and each phase as well as the mean BMD values of all evaluated vertebrae for each individual patient in all phases were documented.

The bone mineral density application also provided a graph, in which the patient's average BMD value was shown in relation to a European reference group ( $\vee$ Fig. 4 ). 


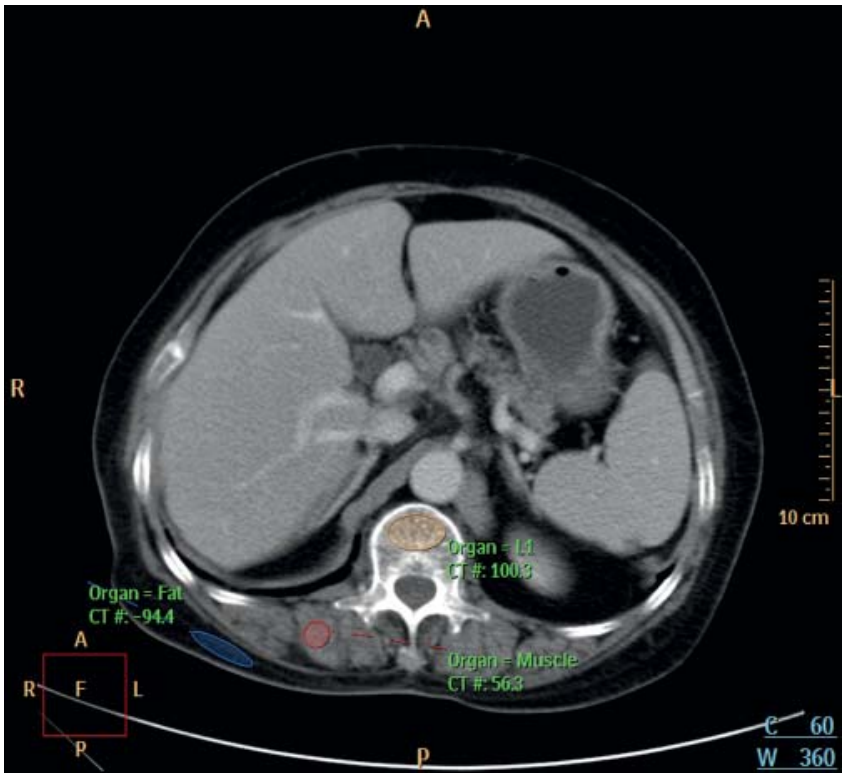

- Fig. 2 Bone mineral density application measurement with three ROls-one in the vertebra (yellow), one in the paraspinal muscle (red), and one in the subcutaneous fat tissue (blue).

- Abb. 2 Phantomlose Knochendichtemessungen mit drei ROls: im Wirbelkörper (gelb), in der paravertebralen Muskulatur (rot) und im subkutanen Fettgewebe (blau).

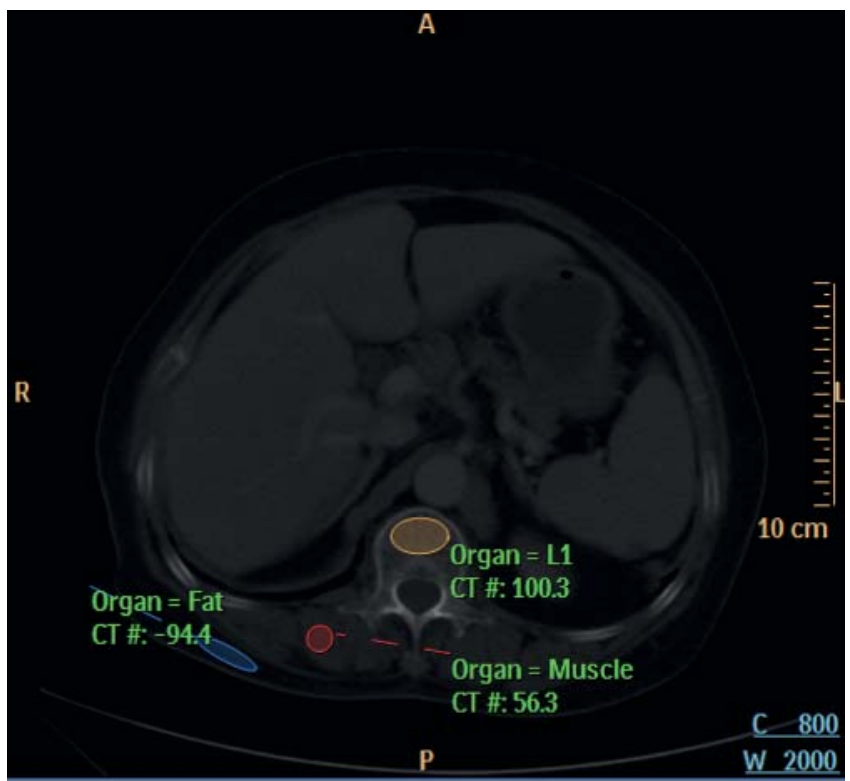

\begin{tabular}{|c|c|c|c|c|}
\hline \multicolumn{5}{|c|}{ Bone Density Results } \\
\hline \hline Vertebra & BMD & T-Score & Z-Score & Date \\
\hline L1 & 60 & -3.2 & -0.5 & 10 Mar 2014 \\
\hline Average & 60 & -3.2 & -0.5 & 10 Mar 2014 \\
\hline
\end{tabular}

- Fig. 3 Bone mineral density application measurement result, BMD of L1: $60 \mathrm{mg} / \mathrm{cm}^{3}$.

- Abb. 3 Ergebnis der phantomlosen Knochendichtemessung, Knochendichte des LWK 1: $60 \mathrm{mg} / \mathrm{cm}^{3}$.

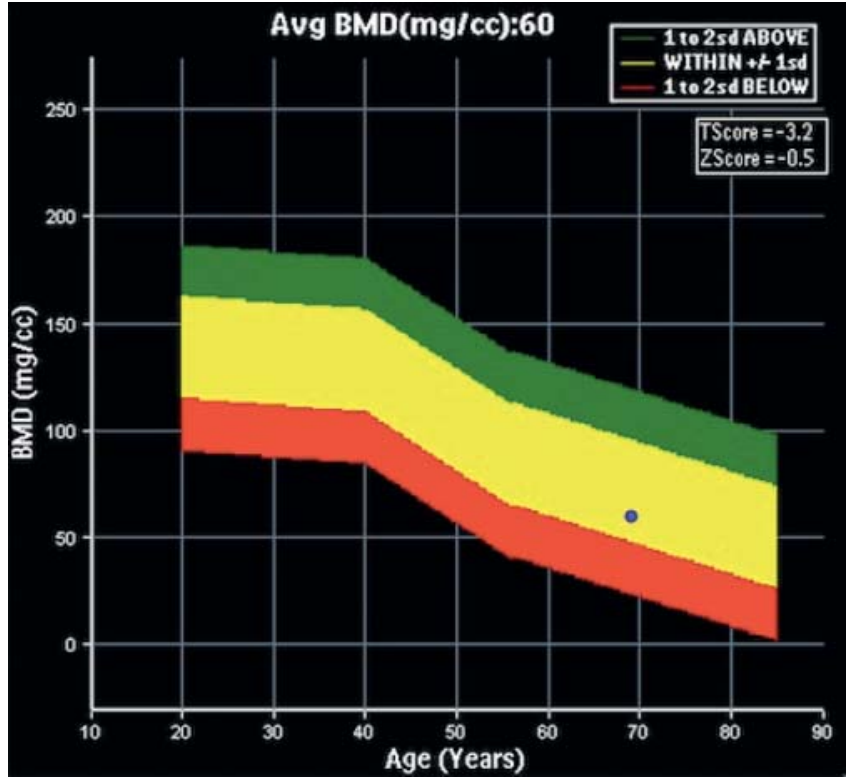

- Fig. 4 Average BMD value in relation to a European reference group.

- Abb. 4 Durchschnittlicher Knochendichtewert in Relation zu einer Europäischen Referenzgruppe.

After a training session with a board-certified radiologist, a medical student in the last academic year performed all BMD evaluations. The BMD application's reproducibility was evaluated using 40 randomly selected patients who were also evaluated by a resident in the third year of training. In order to calculate the intrarater agreement, the medical student evaluated 40 patients twice, blinded to patient-identifying data and previously measured BMD values.

\section{Statistical analyses}

All statistical analyses were performed by a statistician, using IBM SPSS 22.0 .

BMD was described using mean and standard deviation. In order to compare BMD obtained on unenhanced scans and in the arterial and venous phases, repeated measures ANOVA and post hoc Bonferroni corrected paired t-tests were used. By using the linear regression analyses, two conversion formulas for the calculation of BMD values based on the contrast-enhanced phases could be developed. The intra- and interobserver agreement was rated using the intraclass correlation coefficient (ICC). A p-value of $p<0.05$ was considered to indicate significant results.

\section{Results}

Calculating the mean BMD of at least two vertebrae per patient, the mean BMD value of all patients in the unenhanced phase was $79.76 \mathrm{mg} / \mathrm{cm}^{3}$ (SD 31.20). In the arterial phase, the mean BMD value of the whole study population was $85.09 \mathrm{mg} / \mathrm{cm}^{3}$ (SD 31.61), and, in the venous phase, the mean BMD value was calculated at $86.18 \mathrm{mg} / \mathrm{cm}^{3}$ (SD 31.30). 

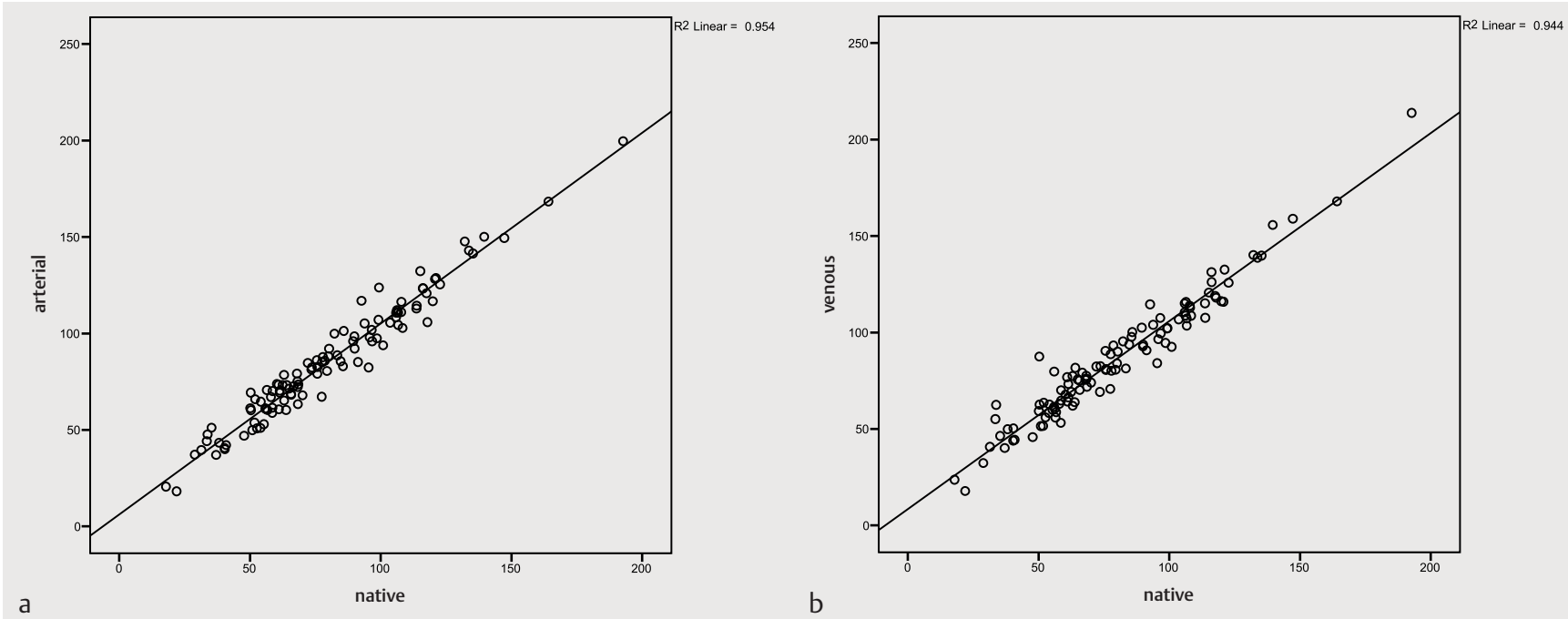

- Fig. 5 Scatter diagrams showing a positive correlation between unenhanced vs. arterial a and unenhanced vs. venous BMD values $\mathbf{b}$.

Abb. 5 Die Streudiagramme zeigen eine positive Korrelation zwischen nativ vs. arteriell a und nativ vs. venös b gemessenen Knochendichtewerten.

Repeated measures ANOVA and post hoc corrected paired t-tests showed that BMD values measured in the unenhanced phase were significantly lower than the values acquired in the venous and arterial phases $(p<0.001)$. However, there was no significant difference found between BMD values calculated in the arterial phase and BMD values measured in the venous phase $(p=0.228)$. Patients undergoing chemotherapy vs. patients without chemotherapy did not demonstrate any significant difference in regard to BMD values $(p=0.123)$. The same applies for smokers and non-smokers $(p=0.200)$.

- Fig. 5a, b visualize a positive correlation when comparing BMD values calculated in the unenhanced MDCT scans versus BMD values measured in the arterial phase (a), and unenhanced measurements versus BMD values in the venous phase (b), without showing outliers. The difference between arterial and unenhanced BMD values, relative to the difference between venous and unenhanced BMD values, is depicted in > Fig. 6 .

Finally, two conversion formulas, enabling calculation of the unenhanced, relatively true BMD value from values measured in the arterial or venous phase, were defined using linear regression:

- Arterial phase: $\mathrm{BMD}=-2.287+0.964 *$ arterial $\mathrm{BMD}$ value

- Venous phase: $\mathrm{BMD}=-4.517+0.978$ * venous $\mathrm{BMD}$ value

The intrarater agreement of BMD measurements was calculated with an intraclass correlation coefficient (ICC) of 0.984 and the interrater reliability was calculated with an ICC of 0.991 .

\section{Discussion}

Our study showed that phantom-less BMD measurements on contrast-enhanced MDCT scans are possible, even though intravenous contrast agent elevates BMD values, which can result in falsely high results. Taking this into account, it is possible to calculate a converted BMD value using the formulas defined in this study.

In comparison to the suggested thresholds for osteoporosis $\left(<80 \mathrm{mg} / \mathrm{cm}^{3}\right)$ and osteopenia (> 80 to $\left.120 \mathrm{mg} / \mathrm{cm}^{3}\right)$ issued by the American College of Radiology, a remarkable observation in our study was the generally low BMD values of our patients, which might be a population-related finding, as former studies have shown lower BMD values in this ethnic population compared to other ethnic populations $[19,20]$. Since we included 59 patients receiving chemotherapy and 6 smokers, which may have an impact on BMD measurements, an additional statistical analysis was conducted: chemotherapy or smoking did not significantly influence BMD values. In addition, a software-related origin is possible, as Mueller et al. also found slightly lower BMD values using the Philips BMD option compared to phantom-based QCT. However, in their study, the values measured by the BMD software were generally only $0.9 \mathrm{mg} / \mathrm{cm}^{3}$ lower than the BMD values calculated by phantom-based QCT, which is a negligibly low difference. Furthermore, they demonstrated a slightly lower precision compared with phantom-based QCT, but, nevertheless, a very good accuracy of the Philips bone mineral density application, with some advantages compared to QCT using a phantom [14].

With regard to phantom-based QCT, a major disadvantage of the method is the need for a phantom. Using the Philips bone mineral density option, no phantom is needed and BMD measurements can be performed retrospectively in any patient who underwent a CT scan for any reason, without the need for another investigation that might cause additional radiation exposure. Furthermore, the phantom-less BMD measurement is a time- and cost-saving method [14, 21].

Previous studies have already investigated the possibility of BMD measurements on routinely performed MDCT scans and the influence of intravenous contrast agent on the measured BMD values $[10,15,16,18,22,23]$. These studies used different methods 


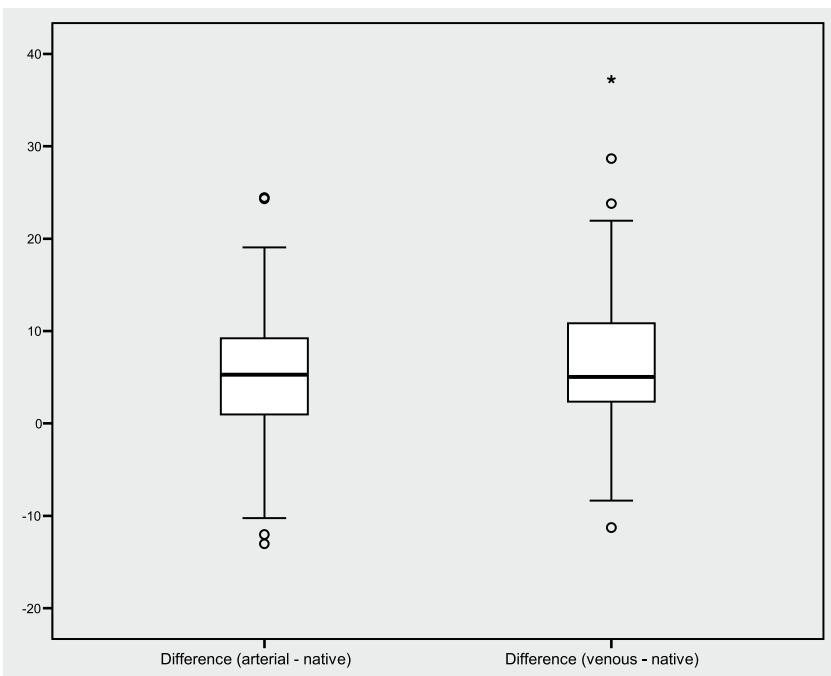

- Fig. 6 Box-and-Whisker plot indicating the difference between arterial-unenhanced and venous-unenhanced BMD values.

- Abb. 6 Der Box-Whisker-Plot veranschaulicht die Differenz zwischen arteriell vs. nativ und venös vs. nativ gemessenen Knochendichtewerten.

and showed somewhat divergent outcomes: Pompe et al. measured attenuation values of L1 in different contrast agent phases and found a significant difference between all phases [15]. In contrast, Pickhardt et al. compared Hounsfield Unit (HU) values of L1 on pre-contrast $\mathrm{CT}$ scans with measurements on contrast-enhanced $\mathrm{CT}$ scans and did not find a significant difference [10, 22]. Some studies, such as the one by Bauer et al., used QCT for BMD evaluation. These investigators described a $2 \%$ increase in BMD values measured in the hip after intravenous contrast agent administration versus a $31 \%$ increase in BMD values measured in the spine [18]. These results correspond very well with the results defined by Link et al., who noted an increase of $30 \%$ in BMD values measured in the spine after intravenous contrast agent administration [16]. Baum et al. compared routine MDCT with a phantom to dedicated phantom-based QCT, and also found an average increase in BMD values of $37.9 \%$, measured in the spine, compared to QCT values [23]. A potential problem when using a phantomless BMD measurement method, where the patient serves as his/ her own reference, might be the variable contrast enhancement of bone, as well as muscle and fat tissue, which leads to increased $\mathrm{HU}$ values of all measurements, and thus, may falsify the calculation algorithm.

Our study has some limitations. We did not correlate our results with the presence of vertebral fractures, as outlined by Baum et al. [23]. Furthermore, the ROIs were placed manually, which gives rise to the risk of a lower precision and a higher interand intraobserver variability. We minimized that risk by providing both observers with an intensive training session before starting the study, thus helping to achieve a very low inter- and intraobserver variability. In contrast to other studies like those of Pompe et al. or Pickhardt et al., our technique requires a specific software tool, which entails additional costs $[10,15]$. Another limitation of this study is that no additional DXA or QCT examinations were available as a reference or for comparison.

\section{Conclusion}

In conclusion, routinely performed contrast-enhanced abdominal MDCT scans can be used for BMD measurement using our method, but the administration of contrast agent should be taken into account. The two formulas defined in this study enable the measurement of BMD values on contrast-enhanced MDCT scans because the actual BMD value can be calculated afterward. The Philips bone mineral density measurement tool used in our study showed very good reliability and seems to be a promising phantom-less method for retrospective BMD measurements on routine MDCT scans.

\section{CLINICAL RELEVANCE OF THE STUDY}

- Using the phantom-less Philips bone mineral density measurement tool tested in this study, BMD measurements can be done retrospectively on any MDCT scan performed for another reason.

- Intravenous contrast media application increases BMD values measured in the arterial as well as venous phases.

- Applying the formulas defined in this study, a reliable BMD value can be calculated from BMD values measured in the arterial or venous phase.

\section{Conflict of Interest}

The authors declare that they have no conflict of interest.

\section{References}

[1] Kanis JA, McCloskey EV, Johansson $\mathrm{H}$ et al. Development and use of FRAX in osteoporosis. Osteoporos Int ] Establ Result Coop Eur Found Osteoporos Natl Osteoporos Found USA 2010; 21: $407-413$

[2] Li N, Li XM, Xu L et al. Comparison of QCT and DXA: Osteoporosis Detection Rates in Postmenopausal Women. Int J Endocrinol 2013; 2013: DOI: 895474

[3] Seeman E. Pathogenesis of bone fragility in women and men. The Lancet 2002; 359: $1841-1850$

[4] Kanis JA, Johansson H, Oden A et al. Assessment of fracture risk. Eur J Radiol 2009; 71: $392-397$

[5] Kanis JA. Diagnosis of osteoporosis and assessment of fracture risk. The Lancet 2002; 359: 1929- 1936

[6] Imai K. Recent methods for assessing osteoporosis and fracture risk. Recent Pat Endocr Metab Immune Drug Discov 2014; 8: 48 - 59

[7] Schuit SCE, van der Klift M, Weel AE et al. Fracture incidence and association with bone mineral density in elderly men and women: the Rotterdam Study. Bone 2004; 34: 195-202

[8] Link TM. Radiology of Osteoporosis. Can Assoc Radiol J 2016; 67: 28 - 40

[9] Gruber M, Bauer JS, Dobritz M et al. Bone mineral density measurements of the proximal femur from routine contrast-enhanced MDCT data sets correlate with dual-energy X-ray absorptiometry. Eur Radiol 2013; 23: $505-512$ 
[10] Pickhardt PJ, Pooler BD, Lauder T et al. Opportunistic screening for osteoporosis using abdominal computed tomography scans obtained for other indications. Ann Intern Med 2013; 158: 588- 595

[11] Forrest L]. Computed Tomography Imaging in Oncology. Vet Clin North Am Small Anim Pract 2016; 46: 499-513

[12] Guise TA. Bone loss and fracture risk associated with cancer therapy. The Oncologist 2006; 11: 1121-1131

[13] Boden SD, Goodenough DJ, Stockham CD et al. Precise measurement of vertebral bone density using computed tomography without the use of an external reference phantom. J Digit Imaging 1989; 2: 31 - 38

[14] Mueller DK, Kutscherenko A, Bartel H et al. Phantom-less QCT BMD system as screening tool for osteoporosis without additional radiation. Eur ] Radiol 2011; 79: 375-381

[15] Pompe E, Willemink MJ, Dijkhuis GR et al. Intravenous contrast injection significantly affects bone mineral density measured on CT. Eur Radiol 2015; 25: $283-289$

[16] Link TM, Koppers BB, Licht T et al. In vitro and in vivo spiral CT to determine bone mineral density: initial experience in patients at risk for osteoporosis. Radiology 2004; 231: 805-811

[17] Hopper KD, Wang MP, Kunselman AR. The use of clinical CT for baseline bone density assessment. J Comput Assist Tomogr 2000; 24: 896-899

[18] Bauer JS, Henning TD, Müeller D et al. Volumetric quantitative CT of the spine and hip derived from contrast-enhanced MDCT: conversion factors. Am J Roentgenol 2007; 188: $1294-1301$
[19] Zhang ZQ, Ho SC, Chen ZQ et al. Reference values of bone mineral density and prevalence of osteoporosis in Chinese adults. Osteoporos Int ] Establ Result Coop Eur Found Osteoporos Natl Osteoporos Found USA 2014; 25: $497-507$

[20] American College of Radiology. ACR Practice Guideline for the Performance of Quantitative Computed Tomography (QCT) Bone Densitometry (Resolution 33) [Internet]. [cited 2016 Oct 14]. Available from: http://www.acr.org/ /media/ACR/Documents/PGTS/guidelines/QCT. pdf

[21] Boomsma MF, Slouwerhof I, van Dalen JA et al. Use of internal references for assessing CT density measurements of the pelvis as replacement for use of an external phantom. Skeletal Radiol 2015; 44: 1597-1602

[22] Pickhardt P], Lauder T, Pooler BD et al. Effect of IV contrast on lumbar trabecular attenuation at routine abdominal CT: correlation with DXA and implications for opportunistic osteoporosis screening. Osteoporos Int J Establ Result Coop Eur Found Osteoporos Natl Osteoporos Found USA 2016; 27: 147 - 152

[23] Baum T, Müller D, Dobritz M et al. BMD measurements of the spine derived from sagittal reformations of contrast-enhanced MDCT without dedicated software. Eur J Radiol 2011; 80: e140-e145 